\title{
Intima media thickness as an early predictor of atherosclerosis in Egyptian children with familial Mediterranean fever
}

\author{
Samia Salah El-Din Mahmoud ${ }^{1}$, Nagwa Abdallah Ismail², Yomna Mohamed Farag ${ }^{1}$, \\ Rania Hamdy Hashem ${ }^{3}$, Mona Hamed Ibrahim ${ }^{4}$, Mohab Mohamed Salah², Andrew Nasif Tous²
}

${ }^{1}$ Department of Pediatrics, Cairo University, Cairo, Egypt

${ }^{2}$ Department of Pediatrics, National Research Centre, Dokki, Egypt

${ }^{3}$ Department of Radiology, Cairo University, Cairo, Egypt

${ }^{4}$ Department of Clinical and Chemical Pathology, National Research Centre, Dokki, Egypt

Submitted: 25 April 2018

Accepted: 2 July 2018

Arch Med Sci Atheroscler Dis 2018; 3, e106-e111

DOI: https://doi.org/10.5114/amsad.2018.77545

Copyright (c) 2018 Termedia \& Banach

\section{Abstract}

Introduction: Familial Mediterranean fever (FMF) is an autosomal recessive disease. It is characterized by recurrent crises of fever and serosal inflammation. Although FMF patients are symptom free in between attacks, subclinical inflammation continues during the attack-free period. Such patients with inflammatory status have an increased risk of atherosclerotic cardiovascular complications. We attempted to elucidate the role of arterial wall thickening as a predictor of early atherosclerosis in children affected by FMF and to clarify the links between carotid intima media thickness and the markers of subclinical inflammation serum amyloid A (SAA), erythrocyte sedimentation rate (ESR), neutrophil-to-lymphocyte ratio (NLR) and platelet lymphocyte ratio (PLR).

Material and methods: It is a case control study. The study comprised 45 Egyptian children diagnosed with FMF and 45 healthy children of matched age and sex who served as controls, without family history or clinical manifestations suggestive of FMF. Laboratory investigations included complete blood count, NLR, PLR, ESR, C-reactive protein and lipid profile. Serum amyloid $A$ levels were determined in both groups using enzyme linked immunosorbent assay. Assessment of the common carotid artery intima media thickness (CIMT) in the FMF patients was carried out.

Results: The level of SAA was significantly higher in patients than the control subjects with a mean value of $38.30 \mathrm{ng} / \mathrm{ml}$ and $23.43 \mathrm{ng} / \mathrm{ml}$ respectively $(p<0.001)$. Our patients showed significantly higher PLR when compared to controls $(p<0.001)$. The mean right and left carotid intima media thickness in patient and control groups showed a highly significant difference ( $p=$ 0.005 and 0.036 respectively).

Conclusions: The mean carotid intima media thickness is higher in cases than the control group. Hence carotid intima media thickness may be used as a tool in the prediction of any atherosclerotic burden in those children.

Key words: familial Mediterranean fever, intima media thickness, atherosclerosis.

\section{Introduction}

Familial Mediterranean fever (FMF) is an autoinflammatory disease that is characterized by recurrent attacks of fever and inflammation in serous

\author{
Corresponding author: \\ Mohab Mohamed Salah \\ National Research Centre \\ Cairo, Egypt \\ Phone: 00201090540700 \\ E-mail: mohap.salah@yahoo. \\ com
}


membranes, joints and skin [1]. Inflammation plays a key role in the pathogenesis of atherosclerosis, which starts by causing endothelial dysfunction, then progresses to cause a change in artery morphology [2]. Platelet activation is a common finding in inflammatory, thrombotic and atherogenic pathways. Activated platelets react with neutrophils and endothelial cells, through the production of $P$ selectin and other pro-inflammatory compounds; this process enhances the role of immune cells in vascular inflammation and atherosclerosis [3].

Carotid intima media thickness (CIMT) is a non-invasive ultrasound screening test for detection of early atherosclerosis. Several studies have found a correlation between it and the risk of cardiovascular attacks [4].

White blood cell count is considered an important inflammatory marker especially in cardiovascular diseases. Platelet-to-lymphocyte ratio $(P L R)$ is associated with chronic inflammation in cardiovascular and autoimmune diseases [5]. This study aims to evaluate arterial wall thickening as a potential marker for early atherosclerosis in FMF patients to correlate CIMT with markers of subclinical inflammation in FMF patients such as serum amyloid $A(S A A)$, erythrocyte sedimentation rate (ESR) and PLR.

\section{Material and methods}

\section{Study design and sample collection}

This was a case control study carried out from January 2016 to May 2016 in which the patient group was represented by 45 Egyptian children diagnosed as FMF cases according to the new FMF criteria [6].

All patients were recruited from and followed up at the pediatric rheumatology clinic, Abou El Rish Pediatric Hospital. All participating patients were older than 7 years old and in an attack-free period.

Forty-five age- and sex-matched healthy children without family history or clinical manifestations suggestive of FMF served as a control group. Exclusion criteria for controls included any concomitant autoimmune disorder, associated congenital heart disease, renal affection, acute infection, or familial hypercholesterolemia.

\section{Methodology}

Blood samples from all participants were withdrawn under complete aseptic conditions. Laboratory investigations for all participants at the time of study including complete blood picture by CELLDYN, neutrophil to lymphocyte ratio (NLR) and PLR were performed, ESR and C-reactive protein were measured by Nephstar, lipid profile including low-density lipoprotein (LDL), high-density lipoprotein (HDL), triglycerides and cholesterol was done by Erba XL-300 and urine analysis for proteinuria quantitative determination of serum amyloid A (SAA) levels was assayed using EIAab ELISA Kit, Co., Ltd, Cat E08885h.

Measurement of the CIMT in the FMF patients was performed by grey scale ultrasonography using GELOGIQ P6 ultrasound system with a 7.5-10 $\mathrm{MHz}$ linear-array transducer.

\section{CIMT measurement}

A single experienced vascular sonographer, who was blind to the clinical and laboratory data of the study subjects, performed all imaging studies. The images were obtained using a General Electric medical ultrasonographic machine (model: GE LOGIQ P6) equipped with a 7.5-10 MHz linear-array transducer. Imaging of the carotid arteries was performed at the radiology department at Abo el Rish Cairo University by a specialized pediatrics hospital, the subject resting in the supine position with his/her neck extended, and the head turned $45^{\circ}$ toward the contralateral side. A transverse section of the common carotid artery was imaged first to screen for any atheromatous plaques and then a longitudinal section at the middle third of the common carotid artery was imaged to achieve a consistent site of measurement. Generally, images are recorded in the plane where the maximal CIMT can be visualized. Magnification of the vessel wall allows easy identification of the intima-medial complex, defined by the border between the echolucent vessel lumen and the echogenic intima and the border between the echolucent media and echogenic adventitia.

\section{Statistical analysis}

Data were coded and entered using the statistical package SPSS (Statistical Package for the Social Sciences) version 23 for Windows (SPSS 23, Inc., Chicago, IL, USA). Data were summarized using mean, standard deviation, median, minimum and maximum for quantitative data and using frequency (count) and relative frequency (percentage) for categorical data. Comparisons between quantitative variables were done using the non-parametric Kruskal-Wallis and Mann-Whitney tests. For comparing categorical data, chi square $\left(\chi^{2}\right)$ test was performed. The exact test was used instead when the expected frequency was less than 5 . Correlations between quantitative variables were done using Spearman correlation coefficient. $P$-values less than 0.05 were considered as statistically significant.

\section{Results}

\section{Demographic data}

All demographic data of patients are summarized in the Table I. 
Samia Salah El-Din Mahmoud, Nagwa Abdallah Ismail, Yomna Mohamed Farag, Rania Hamdy Hashem, Mona Hamed Ibrahim, Mohab Mohamed Salah, Andrew Nasif Tous

\section{Laboratory data}

Platelets to lymphocytic ratio (PLR) mean was found higher in patients group than control group with a highly significant difference $(p<0.001)$ (Table II).

Neutrophils to lymphocytic ratio (NLR) mean was found roughly the same between the cases and the control with no significant difference ( $p=$ 0.765) (Table II).

Erythrocyte sedimentation rate (ESR) was found to be elevated in patients $(p<0.001)$.

C-reactive protein (CRP) was elevated in patients with a significant difference $(p<0.001)$. Also the mean of both ESR and CRP were higher in patients than controls with a highly significant difference $(p<0.001)$ (Table II).

Serum amyloid A level was found higher in the patients group than the control group with a highly significant difference $(p<0.001)$ (Table II).

The lipid profile was done for both groups showing higher levels of cholesterol and LDL in patients $(p<0.001)$ (Table III).

\section{Radiological data}

Regarding the carotid intima media thickness, the mean of the right and left carotid intima media thickness higher in patient than the control group with a highly significant difference $p$-value are 0.005 and 0.036 respectively (Table IV).

Carotid intima media thickness correlation with inflammatory markers as ESR, CRP and SAA but there was no statistical significance $(p>0.005)$ (Table V).

Correlation between mean CIMT, Lipid profile, NLR and PLR showed no statistical significance $(p>0.05)$ (Table VI).

\section{Discussion}

Atherosclerosis and cardiovascular diseases are important causes of morbidity and mortality in FMF patients [7]. Systemic inflammation leads to endothelial dysfunction, which causes oxidative stress, vascular damage and finally atherosclerosis $[8,9]$.

Carotid intima media thickness is a safe, simple, and inexpensive method for evaluating car-

Table I. Demographic data of the studied FMF cases

\begin{tabular}{|c|c|c|c|c|c|}
\hline \multirow[t]{2}{*}{ Parameter } & \multicolumn{5}{|c|}{ Cases } \\
\hline & Mean & $\begin{array}{l}\text { Standard } \\
\text { deviation }\end{array}$ & Median & Minimum & Maximum \\
\hline Age of first symptoms & 5.82 & 2.52 & 6.00 & 1.00 & 10.00 \\
\hline Delay in diagnosis [years] & 3.21 & 1.62 & 3.00 & 0.00 & 7.00 \\
\hline \multirow[t]{3}{*}{ Disease duration [years] } & 5.97 & 1.50 & 5.00 & 5.00 & 10.00 \\
\hline & \multicolumn{5}{|c|}{ Cases } \\
\hline & \multicolumn{2}{|r|}{ Count } & \multicolumn{3}{|c|}{$\%$} \\
\hline First degree consanguinity & \multicolumn{2}{|r|}{14} & \multicolumn{3}{|c|}{31.1} \\
\hline Family history of FMF & \multicolumn{2}{|r|}{13} & \multicolumn{3}{|c|}{28.9} \\
\hline History of appendicectomy & \multicolumn{2}{|r|}{4} & \multicolumn{3}{|c|}{8.9} \\
\hline
\end{tabular}

Table II. Analysis of the inflammatory markers in the studied FMF patients and the controls

\begin{tabular}{|c|c|c|c|c|c|c|c|c|c|c|c|}
\hline \multirow[t]{2}{*}{ Variable } & \multicolumn{5}{|c|}{ Cases } & \multicolumn{5}{|c|}{ Control } & \multirow[b]{2}{*}{$P$-value } \\
\hline & Mean & SD & Median & $\begin{array}{l}\text { Mini- } \\
\text { mum }\end{array}$ & $\begin{array}{l}\text { Maxi- } \\
\text { mum }\end{array}$ & Mean & SD & Median & $\begin{array}{l}\text { Mini- } \\
\text { mum }\end{array}$ & $\begin{array}{l}\text { Maxi- } \\
\text { mum }\end{array}$ & \\
\hline $\begin{array}{l}\text { Neutrophil to } \\
\text { lymphocyte ratio } \\
\text { (NLR) }\end{array}$ & 1.12 & 0.57 & 1.00 & 0.30 & 2.70 & 1.18 & 0.85 & 1.00 & 0.20 & 4.30 & 0.765 \\
\hline $\begin{array}{l}\text { Platelet to } \\
\text { lymphocyte ratio } \\
\text { (PLR) }\end{array}$ & 118.89 & 39.41 & 115.00 & 58.80 & 208.90 & 84.33 & 34.00 & 76.70 & 28.50 & 195.00 & $<0.001^{*}$ \\
\hline ESR value & 15.51 & 17.84 & 11.00 & 0.00 & 108.00 & 7.40 & 2.66 & 7.00 & 4.00 & 15.00 & $<0.001^{*}$ \\
\hline CRP value & 9.48 & 34.43 & 0.00 & 0.00 & 170.00 & 0.00 & 0.00 & 0.00 & 0.00 & 0.00 & $<0.001^{\star}$ \\
\hline $\begin{array}{l}\text { Serum amyloid } \\
\mathrm{A}[\mathrm{ng} / \mathrm{ml}]\end{array}$ & 38.30 & 21.51 & 34.70 & 11.60 & 114.80 & 23.43 & 8.02 & 23.40 & 6.50 & 38.10 & $<0.001^{\star}$ \\
\hline
\end{tabular}


Table III. Lipid profile of patients and controls

\begin{tabular}{|c|c|c|c|c|c|c|c|c|c|c|c|}
\hline \multirow[t]{2}{*}{ Parameter } & \multicolumn{5}{|c|}{ Cases } & \multicolumn{5}{|c|}{ Control } & \multirow[t]{2}{*}{$P$-value } \\
\hline & Mean & SD & Median & $\begin{array}{l}\text { Mini- } \\
\text { mum }\end{array}$ & $\begin{array}{l}\text { Maxi- } \\
\text { mum }\end{array}$ & Mean & SD & Median & $\begin{array}{l}\text { Mini- } \\
\text { mum }\end{array}$ & $\begin{array}{l}\text { Maxi- } \\
\text { mum }\end{array}$ & \\
\hline $\begin{array}{l}\text { LDL level } \\
{[\mathrm{mg} / \mathrm{dl}]}\end{array}$ & 107.49 & 32.30 & 107.00 & 54.00 & 219.00 & 82.96 & 22.43 & 83.00 & 42.00 & 141.00 & $<0.001^{\star}$ \\
\hline $\begin{array}{l}\text { HDL level } \\
{[\mathrm{mg} / \mathrm{dl}]}\end{array}$ & 38.16 & 13.93 & 38.00 & 18.00 & 79.00 & 42.44 & 9.26 & 41.00 & 22.00 & 63.00 & $0.049^{*}$ \\
\hline $\begin{array}{l}\text { Triglycerides } \\
{[\mathrm{mg} / \mathrm{dl}]}\end{array}$ & 80.04 & 31.25 & 73.00 & 43.00 & 162.00 & 75.44 & 15.02 & 75.00 & 55.00 & 116.00 & 0.599 \\
\hline $\begin{array}{l}\text { Cholesterol } \\
\text { level [mg/dl] }\end{array}$ & 162.04 & 31.21 & 162.00 & 100.00 & 271.00 & 140.71 & 21.23 & 140.00 & 101.00 & 190.00 & $<0.001^{*}$ \\
\hline
\end{tabular}

Table IV. Comparison between FMF patients and controls as regards right and left CIMT

\begin{tabular}{|c|c|c|c|c|c|c|c|c|c|c|c|}
\hline \multirow[t]{2}{*}{ Variable } & \multicolumn{5}{|c|}{ Cases } & \multicolumn{5}{|c|}{ Control } & \multirow[t]{2}{*}{$P$-value } \\
\hline & Mean & SD & Median & $\begin{array}{c}\text { Mini- } \\
\text { mum }\end{array}$ & $\begin{array}{c}\text { Maxi- } \\
\text { mum }\end{array}$ & Mean & SD & Median & $\begin{array}{l}\text { Mini- } \\
\text { mum }\end{array}$ & $\begin{array}{c}\text { Maxi- } \\
\text { mum }\end{array}$ & \\
\hline $\begin{array}{l}\text { Right carotid } \\
\text { intima media } \\
\text { thickness }\end{array}$ & 0.05 & 0.01 & 0.05 & 0.03 & 0.06 & 0.04 & 0.01 & 0.04 & 0.03 & 0.06 & $0.005^{\star}$ \\
\hline $\begin{array}{l}\text { Left carotid } \\
\text { intima media } \\
\text { thickness }\end{array}$ & 0.05 & 0.01 & 0.05 & 0.02 & 0.07 & 0.04 & 0.01 & 0.04 & 0.03 & 0.06 & $0.036^{*}$ \\
\hline
\end{tabular}

Table V. Correlation between mean CIMT, ESR, CRP and SAA

\begin{tabular}{|c|c|c|c|c|c|c|}
\hline \multirow[t]{2}{*}{ Variable } & \multicolumn{5}{|c|}{ Mean CIMT } & \multirow[t]{2}{*}{$P$-value } \\
\hline & Mean & $\begin{array}{l}\text { Standard } \\
\text { deviation }\end{array}$ & Median & Minimum & Maximum & \\
\hline ESR & 0.05 & 0.00 & 0.05 & 0.04 & 0.06 & 0.934 \\
\hline \multirow[t]{2}{*}{ CRP $[\mathrm{mg} / \mathrm{dll}]$} & 0.05 & 0.01 & 0.05 & 0.04 & 0.06 & 0.207 \\
\hline & & & & \multicolumn{3}{|c|}{ Serum amyloid $A$ [ng/ml] } \\
\hline \multirow[t]{2}{*}{ Mean CIMT } & & $R$ & & \multicolumn{3}{|c|}{0.021} \\
\hline & & $P$-value & & \multicolumn{3}{|c|}{0.890} \\
\hline
\end{tabular}

Table VI. Correlation between mean CIMT, lipid profile, NLR and PLR

\begin{tabular}{|lll|}
\hline Parameter & & Mean CIMT \\
\hline LDL level [mg/dl] & Correlation coefficient & 0.223 \\
\cline { 2 - 3 } & $P$-value & 0.141 \\
\hline HDL level [mg/dl] & Correlation coefficient & -0.272 \\
\cline { 2 - 3 } & P-value & 0.071 \\
\hline Triglycerides [mg/dl] & Correlation coefficient & -0.029 \\
\cline { 2 - 3 } & $P$-value & 0.848 \\
\hline Cholesterol level [mg/dl] & Correlation coefficient & 0.109 \\
\cline { 2 - 3 } & $P$-value & 0.474 \\
\hline Neutrophil to lymphocyte ratio (NLR) & Correlation coefficient & 0.180 \\
\cline { 2 - 3 } & $P$-value & 0.236 \\
\hline Platelet to lymphocyte ratio (PLR) & Correlation coefficient & 0.228 \\
\cline { 2 - 3 } & $P$-value & 0.133 \\
\hline
\end{tabular}


diovascular risk by measuring the combined thickness of the intima and medial layers of the arterial wall [10].

A study was done by Dușunsel et al. [11], who reported that $30.4 \%$ of their patients had consanguineous parents and $26.5 \%$ of patients had a positive family history of FMF. Another Turkish study by Kilic et al. [12] displayed a positive family history in $44.6 \%$ of the studied patients. An Iranian study presented by Salehzadeh et al. [13] reported that $20 \%$ of their patients had positive family history of FMF, while parental consanguinity was present in $50 \%$ of the patients. We revealed positive family history of FMF in $28.9 \%$ of our studied cases and 14 out of the 45 cases showed first degree consanguinity.

In our study, we tried to focus on carotid intima media thickness (CIMT) as a marker of early atherosclerosis in Egyptian children with FMF. CIMT is considered a reflection of early arterial wall morphological changes caused by many risk factors over a period of time and it is considered a noninvasive marker of premature atherosclerosis [14].

The mean of the right and left CIMT in our FMF patients was higher than controls with a significant difference ( $p$ values are 0.005 and 0.036 respectively).

Our results matched the study offered by Peru et al., [14] where the mean of the CIMT in patients versus controls was $0.038 \pm 0.007$ in patients vs. $0.032 \pm 0.004$ in controls, as well as another study done by Bilginer et al. [15], where the mean in patients was higher than controls (0.03 and 0.02) respectively.

Other studies that were done in adults with FMF matched our results, such as the study done by Gürbüz et al. [16]. Another study that was conducted by Akdogan et al. [17] showed that the mean CIMT in patients was higher than the mean in the controls $0.06 \pm 0.07$ and $0.05 \pm 0.07$ respectively. Another Turkish study by Ugurlu et al. [18] showed similar results where the mean CIMT was $0.05 \pm 0.01$ in patients and $0.04 \pm 0.01$ in the controls. This agreement among different studies suggests the increased risk of atherosclerotic burden in FMF patients, which needs to be monitored closely.

On the other hand, a study carried out by Sari et al. [19] showed that there was no difference between the mean CIMT in both FMF patients and the control group. Regarding the correlation between CIMT and the lipid profile, our results showed no correlation between CIMT and lipid profile. Our results matched the study done by Peru et al. [14] and Sari et al. [19]. This finding might reflect the ability of CIMT to be an early predictor of atherosclerotic risk.
Our results go hand in hand with other studies that tried to link CIMT with lipid profile in diseases other than FMF, like the Egyptian study done by Kandil et al. [20] on children with obesity that also failed to find a correlation between CIMT and lipid profile. On the other hand, a study done by Ugurlu et al. [18] encompassing adult FMF patients revealed positive correlation between CIMT and total cholesterol level and LDL. Again, the difference may be due to different numbers of patients and different study methodologies. The study done by Abd el dayem et al. [10], which measured CIMT in type $1 \mathrm{DM}$ in adolescents, found a positive correlation between CIMT and cholesterol level and triglycerides.

In our study there was no significant correlation between CIMT and SAA. This result matched the studies done by Peru et al. [14] and Ugurlu et al. [18]. In contrast a study by Bilginer et al. [15] revealed a significant correlation between CIMT and SAA. This may be because of different study methodologies.

No significant correlation was found between CIMT and CRP. Our results matched the studies done by Peru et al. [14], Ugurlu et al. [18], and Bilginer et al. [15]. This might be due to the fact that CIMT needs more time to be affected by subclinical inflammation than the subclinical markers.

No significant correlation was found between CIMT and ESR. Our results matched the study done by Ugurlu et al. [18]. On the other hand the Turkish study reported by Bilginer et al. [15] showed a significant correlation between CIMT and ESR. This may be due to different ethnic groups and the degree of the disease severity.

Recent studies implicated the role of platelets in triggering inflammation of arterial wall [21]. Hence PLR for both patient and control groups were calculated showing a mean of 118.89 and 84.33 respectively with a statistically significant $p<0.001$; these results matched the study by Ozer et al. [22].

Our study displayed a higher risk of atherosclerosis in Egyptian children with FMF than their normal counterparts. CIMT can be considered a useful noninvasive tool to detect early arterial morphological changes in FMF patients for appropriate cardiovascular care settings and follow-up.

\section{Acknowledgments}

We would like to extend our gratitude to all the contributing authors for their sincere efforts.

The study has been approved by the Ethical Committee of the National Research Centre, which is in accordance with the ethical standards of the Declaration of Helsinki and its later amendments. In addition, written informed consent was obtained from parents of each participant prior to their inclusion in the study. 


\section{Conflict of interest}

The authors declare no conflict of interest.

\section{References}

1. Ombrello M, Kastner D. Expanding clinical spectrum and broadening therapeutic horizons. Nat Rev Rheumatol 2011; 7: 82-4.

2. De Groot E, Sander I van L, Duivenvoorden R, et al. Measurement of carotid intima-media thickness to assess progression and regression of atherosclerosis. Nat Clin Pract Cardiovasc Med 2008; 5: 280-8.

3. De Leeuw K, Smit A, de Groot E, van Roon A, Kallenberg C, Bijl M. Longitudinal study on premature atherosclerosis in patients with systemic lupus erythematosus. Atherosclerosis 2009; 206: 546-50.

4. Lorenz M, Polak J, Kavousi M, et al. Carotid intima-media thickness progression to predict cardiovascular events in the general population (the PROG-IMT collaborative project): a meta-analysis of individual participant data. Lancet 2012; 379: 2053-62.

5. Ahsen A, Ulu M, Yuksel S, et al. As a new inflammatory marker for familial Mediterranean fever: neutrophil-to-lymphocyte ratio. Inflammation 2013; 36: 1357-62.

6. Yalçinkaya F, Ozen S, Ozçakar ZB, et al. A new set of criteria for diagnosis of familial Mediterranean fever in childhood. Rheumatology 2009; 48: 395-8.

7. Gasparyan A, Stavropoulos-Kalinoglou A, Mikhailidis D, Toms T, Douglas KMJ, Kitas G. The rationale for comparative studies of accelerated atherosclerosis in rheumatic diseases. Curr Vasc Pharmacol 2010; 8: 437-49.

8. Yüksel S, Ayvazyan L, Gasparyan A. Familial Mediterranean fever as an emerging clinical model of atherogenesis associated with lowgrade inflammation. Open Cardiovasc Med J 2010; 4: 51-6.

9. Şahin A, Erten Ş, Altunoğlu A, et al. Comparison of serum oxidant and antioxidant parameters in familial Mediterranean fever patients (FMF) with attack free period. Acta Reumatol Port 2014; 39: 316-21.

10. Abd El Dayem S, El Bohy A, Battah A. Carotid intimal medial thickness and its relation to endothelial dysfunction and echocardiographic changes in adolescents with type 1 diabetes. J Pediatr Endocrinol Metab 2015; 28: 1029-37.

11. Duşunsel R, Dursun I, GündüzZ, Poyrazoğlu M, Gürgöze M, Dundar M. Genotype-phenotype correlation in children with familial Mediterranean fever in a Turkish population. Pediatr Int 2008; 50: 208-12.

12. Kilic A, Varkal MA, Durmus MS, et al. Relationship between clinical findings and genetic mutations in patients with familial Mediterranean fever. Pediatr Rheumatol J 2015; 13: 59.

13. Salehzadeh F, Emami D, Zolfegari AA, et al. Familial Mediterranean fever in northwest of Iran (Ardabil): the first global report from Iran. Turk J Pediatr 2008; 50: 40-4.

14. Peru H, Altun B, Doğan M, Kara F, Elmaci AM, Oran B. The evaluation of carotid intima-media thickness in children with familial Mediterranean fever. Clin Rheumatol 2008; 27: 689-94.

15. Bilginer Y, Ozaltin F, Basaran C, et al. Evaluation of intima media thickness of the common and internal carotid arteries with inflammatory markers in familial Mediterranean fever as possible predictors for atherosclerosis. Rheumatol Int 2008; 28: 1211-6.

16. Gürbüz Ö, Bagci B, Huzmeli C, Bagci G, Candan F. Glutathione-S-transferase variants are not associated with increased carotid intima-media thickness in Turkish familial Mediterranean fever patients. Arch Rheumatol 2016; 31: 112-20.

17. Akdogan A, Calguneri M, Yavuz B, et al. Are familial Mediterranean fever (FMF) patients at increased risk for atherosclerosis? Impaired endothelial function and increased intima media thickness are found in FMF. J Am Coll Cardiol 2006; 48: 2351-3.

18. Ugurlu S, Seyahi E, Cetinkaya F, Ozbakir F, Balci H, Ozdogan $\mathrm{H}$. Intima-media thickening in patients with familial Mediterranean fever. Rheumatology 2009; 48: 911-5.

19. Sari I, Karaoglu O, Can G, et al. Early ultrasonographic markers of atherosclerosis in patients with familial Mediterranean fever. Clin Rheumatol 2007; 26: 1467-73.

20. Kandil M, Anwar G, Fatouh A, et al. Relation between serum homocysteine and carotid intima-media thickness in obese Egyptian children. J Clin Basic Cardiol 2010; 13: 8-11.

21. Borissoff J, Spronk M, Cate H. The hemostatic system as a modulator of atherosclerosis. N Engl J Med 2011; 364: 1746-60.

22. Ozer S, Yilmaz R, Sonmezgoz E, et al. Simple markers for subclinical inflammation in patients with familial Medeterranian fever. Med Sci Monti 2015; 21: 298-303. 